\title{
TECNOLOGÍA LÍTICA Y CONJUNTO DE ARTEFACTOS UTILIZADOS DURANTE EL POBLAMIENTO TEMPRANO DE URUGUAY*
}

\author{
LITHIC TECHNOLOGY AND TOOLKITS USED DURING \\ THE PEOPLING OF URUGUAY
}

Rafael Suárez $z^{1}$

El artículo avanza en diferentes aspectos de la tecnología lítica y el conjunto de artefactos utilizados durante el poblamiento de Uruguay. La investigación del sitio Pay Paso 1 permitió identificar, a partir de observaciones estratigráficas, arqueológicas y de una sólida base de 31 edades $\mathrm{C}^{14}$, tres componentes culturales tempranos (entre 12.802 y 10.176 años calendario antes del presente). Se observa en Pay Paso 1 la presencia de hojas y núcleos de extracción de las mismas en los componentes tempranos. Los artefactos recuperados durante la excavación del sitio permiten definir parte del conjunto de artefactos utilizado por los cazadores-recolectores tempranos, destacándose diferentes diseños de puntas de proyectil, bifaces, raederas, cuchillos y artefactos sobre hojas.

Palabras claves: tecnología de hojas, puntas de proyectil tempranas, paleoamericanos, poblamiento temprano Uruguay.

This paper considers different aspects of lithic technology and the toolkits used during the peopling of Uruguay. At the site of Pay Paso 1, three early cultural components were identified from chronological, stratigraphic, and archaeological observations. We recorded blades and blade cores in the early components of Pay Paso 1 site. Artifacts recovered during the excavation of the site allowed the definition of the weaponry and toolkits used by the early hunters, featuring different styles of projectile points, bifaces, side-scrapers, knives, and artifacts made on blades. A solid base of $31{ }^{14} \mathrm{C}$ analyses provides a range of dates between 12,802 and 10,176 y cal BP.

Key words: Blade technology, early projectile points, paleoamerican, peopling of Uruguay.

Históricamente la investigación sobre los cazadores-recolectores tempranos en Uruguay prestó atención a un solo tipo de artefacto, las hoy clásicas y conocidas puntas Fell 1 o "Cola de Pescado", sobre las cuales hay una amplia bibliografía generada desde finales del siglo XIX (Figueira 1892) y mediados del siglo XX (Bird 1969). Durante los últimos 30 años se ha renovado el interés por esta clase de artefacto (Bosch et al. 1980; Castiñeira 2011; Flegenheimer et al. 2003; Nami 2007; Politis 1991; Suárez 2000, 2006; Suárez y López 2003). Sin embargo, es muy poco lo que se avanzó o se conoce con relación al conjunto de artefactos utilizados durante el poblamiento.

La investigación realizada en Pay Paso 1 (Figura 1) permitió generar una sólida base cronológica y estratigráfica para una secuencia de ocupaciones humanas en el río Cuareim (cuenca del río Uruguay medio) durante el Pleistoceno Final y Holoceno Temprano. El análisis estratigráfico, la distribución vertical y horizontal de los artefactos en la excavación arqueológica y una serie extensa de 31 edades $\mathrm{C}^{14}$ (Tabla 1) permitieron avanzar desde una resolución cronológica y arqueológica fina sobre el reconocimiento del conjunto de artefactos presente en los tres componentes culturales tempranos interestratificados identificados en el sitio.

El principal objetivo del artículo es profundizar el conocimiento de la tecnología lítica y del conjunto de artefactos provenientes de contextos excavados y datados durante la transición Pleistoceno Holoceno ca. 13.000 y 10.200 años cal. a.p. ${ }^{1}(\sim 11.000-9.100$ años a.p.) en el Noroeste de Uruguay. Los nuevos diseños de puntas de proyectil tempranas indican que existió una interesante diversidad sociocultural durante el final del Pleistoceno y Holoceno Temprano. Los resultados obtenidos permitirán aportar nuevos elementos a la discusión del poblamiento de Uruguay y el suroeste de América del Sur.

* This article was originally presented at the "Early Lithic Technologies: Beyond Regional Projectile Point Typologies" Symposium at the 77th SAA Meeting Memphis, Tennessee, April 2012. Guest editor Kurt Rademaker and César Méndez conducted the peer-review process following the Journal's edition policies.

1 Departamento de Arqueología, Facultad de Humanidades y Ciencias de la Educación, Universidad de la República y Sistema Nacional de Investigadores SNI-ANII. Magallanes 1577, Montevideo, Uruguay. rsuarez@ fhuce.edu.uy 


\section{Sitio Pay Paso 1}

El sitio Pay Paso $1\left(30^{\circ} 16^{\prime} 06,68^{\prime \prime} \mathrm{S}-5^{\circ} 27^{\prime}\right.$ $38.65^{\prime} \mathrm{W}$ ) se ubica en las planicies del río Cuareim en un paso natural entre los actuales territorios de Uruguay y Brasil (Figura 1). Es uno de los nueve sitios de interés arqueológico, paleontológico y paleovegetacional de la localidad Pay Paso (Figura 2). El sitio fue investigado inicialmente durante la década de 1970 por Austral (1995:213) quien aportó una edad para el Holoceno Temprano de 9.890 años a.p.

En el año 2000 se reanudó la investigación en Pay Paso 1 realizando tres nuevas excavaciones que totalizan una superficie de $114 \mathrm{~m}^{2}$ (Figura 3). Los estudios geoarqueológicos indican que los sedimentos de Pay Paso 1 son posteriores al final del Último Máximo Glacial 16.000 años cal a.p. (Piñeiro y Suárez 2012) y exhiben evidencias de

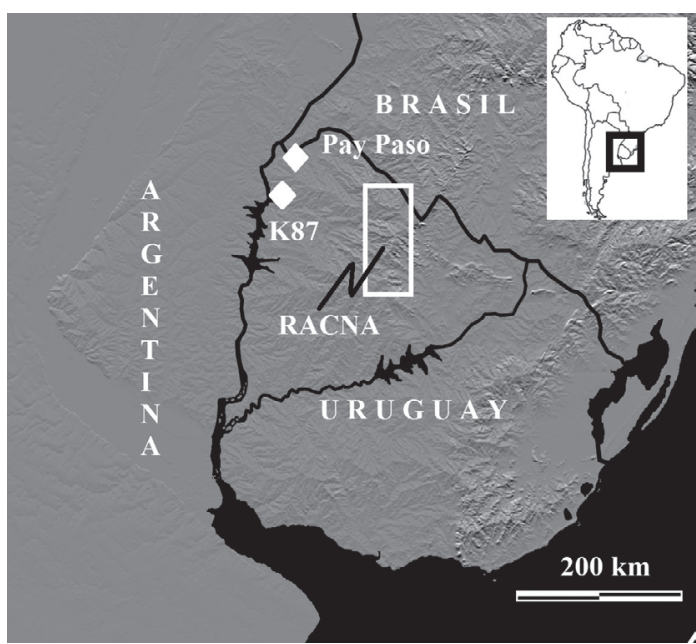

Figura 1. Ubicación de los sitios Pay Paso, K87 (Arroyo del Tigre) y la Región Arqueológica Catalanes Nacientes Arapey RACNA. Location of the Pay Paso and K87 (Arroyo del Tigre) sites and Región Arqueológica Catalanes Nacientes Arapey RACNA.

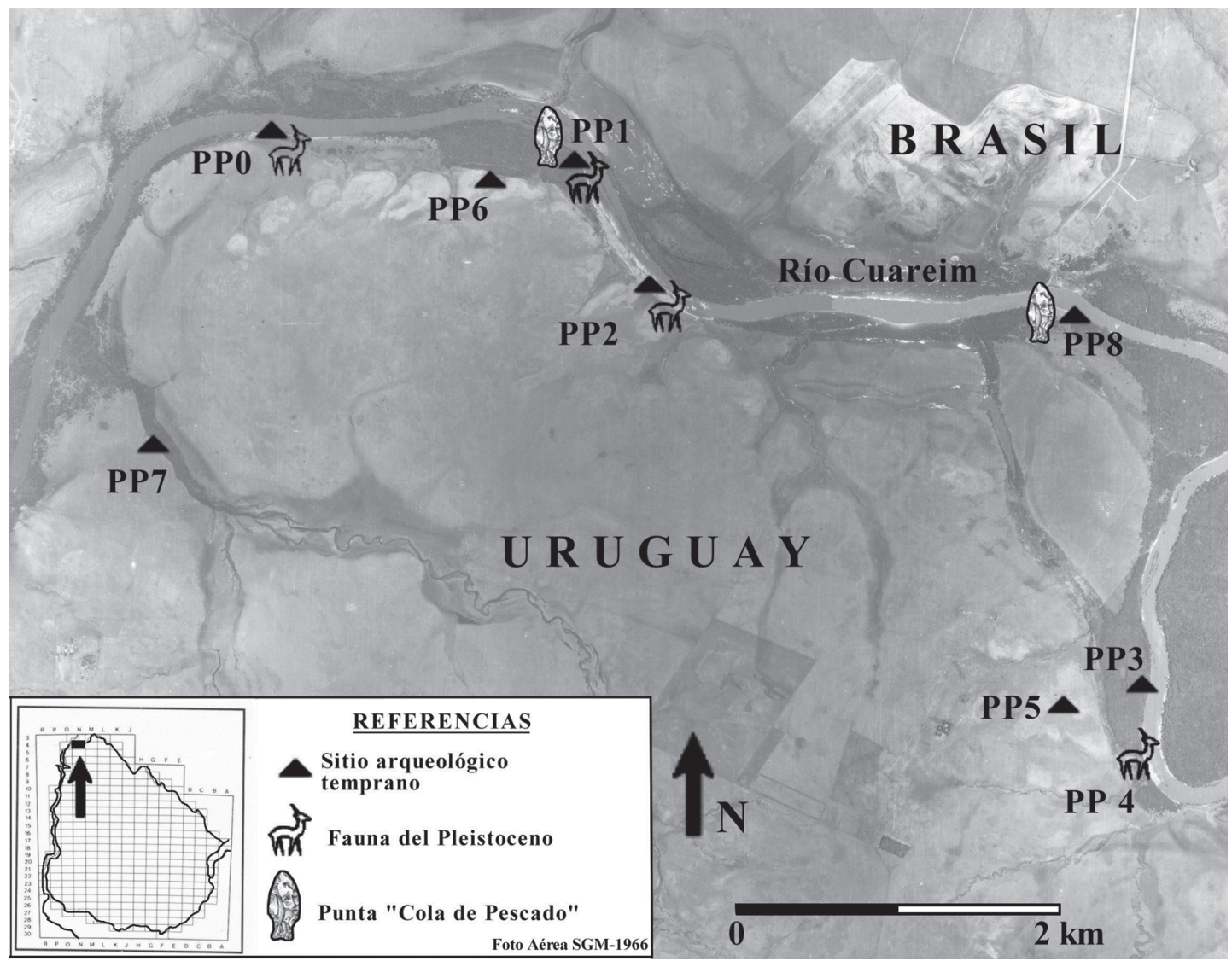

Figura 2. Detalle de la localidad Pay Paso y el sitio Pay Paso 1 (PP1). Detail of the Pay Paso site and Pay Paso 1 locality (PP1). 


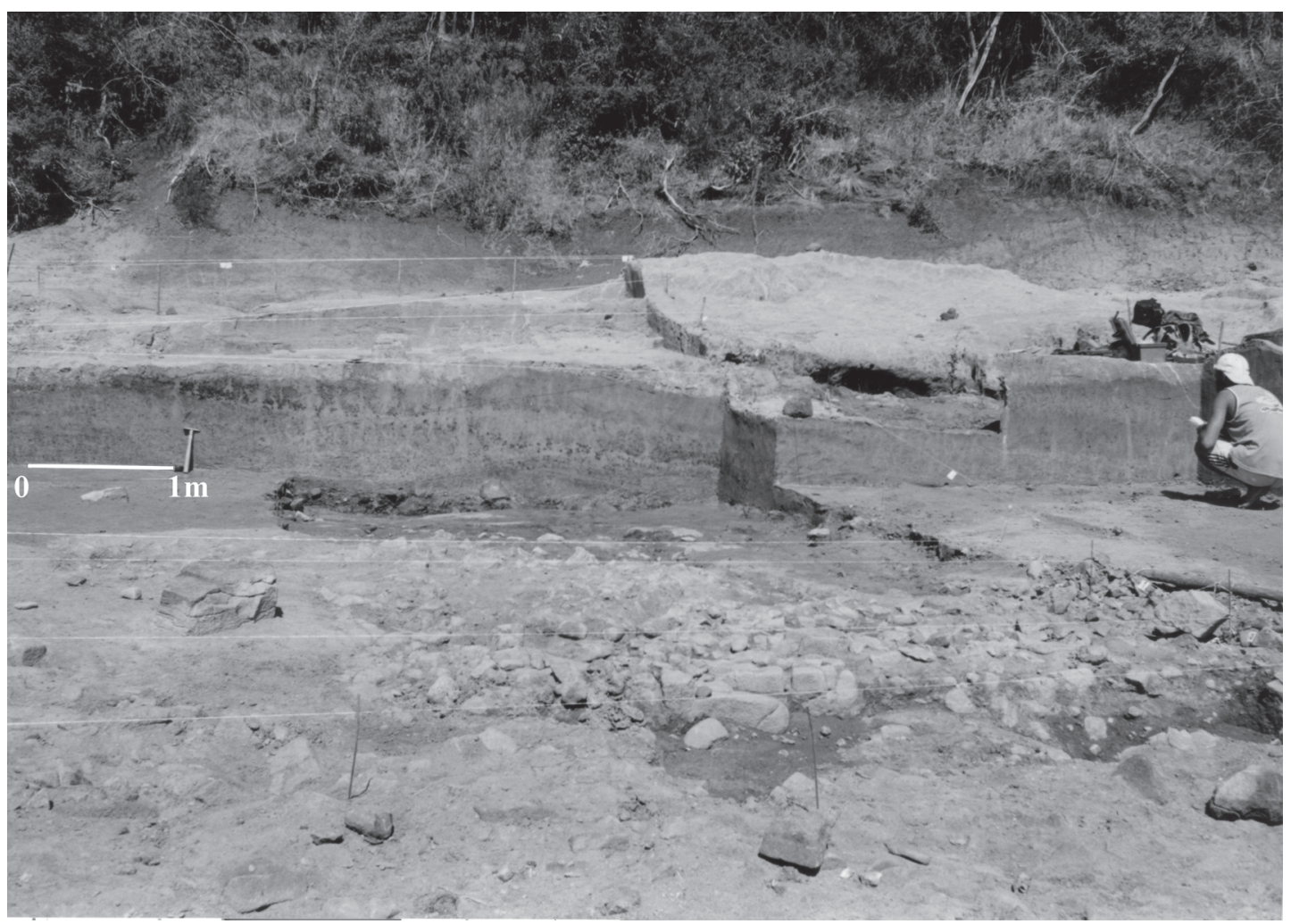

Figura 3. Vista general de la excavación del sitio Pay Paso 1.

General view of the Pay Paso 1 excavation area.

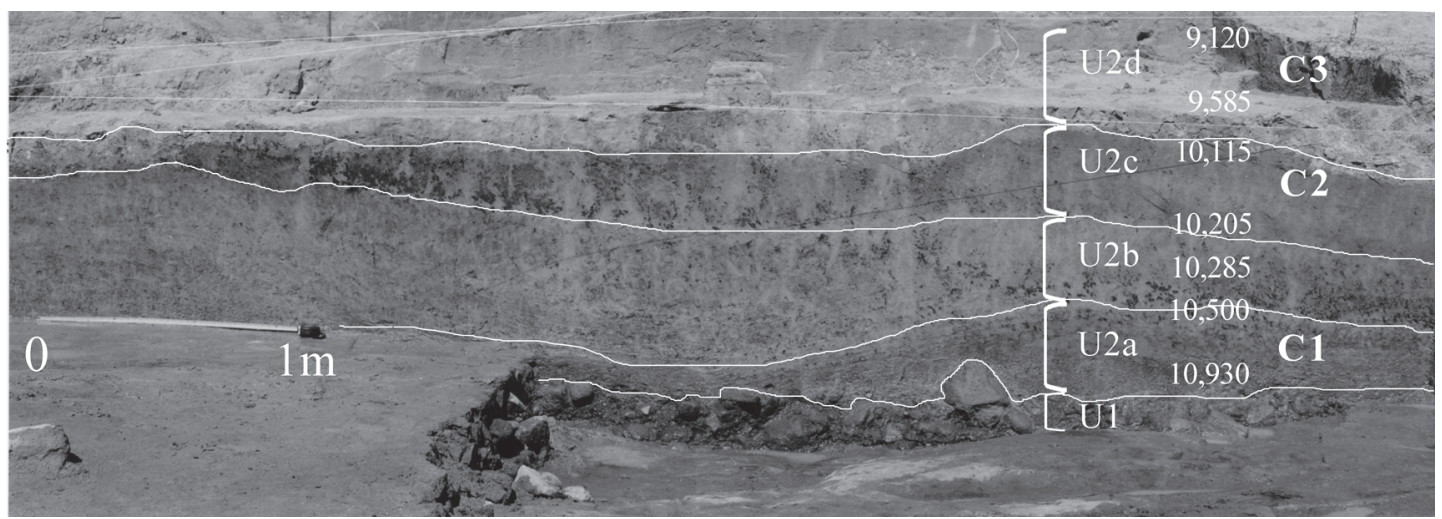

Figura 4. Perfil estratigráfico de la porción inferior del sitio Pay Paso 1 en la zona de excavación. Componentes culturales: Componente $1=\mathrm{C} 1$, Componente 2 = C2 y Componente 3 = C3. Unidades estratigráficas: U1, U2a, U2b, U2c, U2d.

Lower portion of the stratigraphic profile of the Pay Paso 1 site excavation area. Cultural components: C1 Component 1, C2 Component 2, and C3 Component 3. Stratigraphic units: U1, U2a, U2b, U2c, U2d.

importantes fluctuaciones climáticas y ambientales en el transcurso de los últimos 13.000 años cal. a.p. Mediante estudios estratigráficos y de las cronologías obtenidas se definieron tres componentes culturales tempranos en el sitio (Figura 4).
El componente 1 se dató a partir de 12 edades $\mathrm{C}^{14}$ por AMS y abarca un lapso de entre $12.802 \mathrm{y}$ 12.470 años cal. a.p. (Tabla 1). Se ubica en la base del perfil sedimentario en la unidad estratigráfica U2a (Figura 4) donde se recuperaron una serie 
Tabla 1. Edades $\mathrm{C}^{14}$ por AMS obtenidas en el sitio Pay Paso 1 AMS ages from Pay Paso 1 site.

\begin{tabular}{|c|c|c|c|c|}
\hline $\begin{array}{c}\text { Número } \\
\text { Laboratorio }\end{array}$ & $\begin{array}{l}\text { Edad radiocarbónica } \\
\qquad\left(\mathrm{C}^{14} \text { años a.p. }\right)\end{array}$ & $\delta_{\% o}^{13} \mathrm{C}$ & $\begin{array}{c}2 \sigma \\
\text { Edad calendario } \\
\left(_{(\text {años cal. a.p. })^{\mathrm{a}}}\right.\end{array}$ & $\begin{array}{l}\text { Componente Cultural } \\
\text { Unidad estratigráfica }\end{array}$ \\
\hline UCIAMS 21631 & $10.930 \pm 20$ & $-22,0$ & $12.802-12.705$ & Componente 1 - U2a \\
\hline UCIAMS 27738 & $10.910 \pm 30$ & $-25,6$ & $12.797-12.698$ & Componente 1- U2a \\
\hline UCIAMS 27744 & $10.895 \pm 30$ & $-24,9$ & $12.894-12.712$ & Componente 1 - U2a \\
\hline UCIAMS 27745 & $10.880 \pm 25$ & $-24,9$ & $12.759-12.692$ & Componente 1 - U2a \\
\hline UCIAMS 21637 & $10.680 \pm 20$ & $-22,4$ & $12.674-12.612$ & Componente 1 - U2a \\
\hline UCIAMS 21636 & $10.630 \pm 25$ & $-26,4$ & $12.655-12.547$ & Componente 1 - U2a \\
\hline UCIAMS 27746 & $10.595 \pm 30$ & $-27,2$ & $12.642-12.589$ & Componente 1 - U2a \\
\hline UCIAMS 21644 & $10.580 \pm 20$ & $-25,5$ & $12.618-12.604$ & Componente 1 - U2a \\
\hline UCIAMS 21645 & $10.555 \pm 20$ & $-24,3$ & $12.552-12.462$ & Componente 1 - U2a \\
\hline UCIAMS 27747 & $10.540 \pm 35$ & $-27,1$ & $12.629-12,602$ & Componente 1 - U2a \\
\hline UCIAMS 21643 & $10.520 \pm 20$ & $-25,5$ & $12.551-12,466$ & Componente 1 - U2a \\
\hline UCIAMS 27740 & $10.500 \pm 25$ & $-26,2$ & $12.548-12.470$ & Componente 1 - U2a \\
\hline UCIAMS 28692 & $10.465 \pm 30$ & - & $12.429-12.361$ & Estéril - U2b \\
\hline UCIAMS 28682 & $10.450 \pm 25$ & - & $12.422-12.361$ & Estéril - U2b \\
\hline UCIAMS 27741 & $10.390 \pm 30$ & $-25,1$ & $12.400-12.327$ & Estéril - U2b \\
\hline RT 5257 & $10,320 \pm 70$ & $-24,6$ & $12.401-12.326$ & Estéril - U2b \\
\hline UCIAMS 21639 & $10.285 \pm 25$ & $-28,3$ & $12.051-11.821$ & Estéril - U2b \\
\hline RT 5256 & $10.225 \pm 70$ & $-24,7$ & $12.251-12.244$ & Estéril - U2b \\
\hline UCIAMS 21632 & $10.205 \pm 35$ & $-19,8$ & $12.008-11.697$ & Componente 2 - U2c \\
\hline UCIAMS 21634 & $10.180 \pm 20$ & $-19,8$ & $11.974-11.859$ & Componente 2 - U2c \\
\hline UCIAMS 21633 & $10.115 \pm 25$ & $-21,9$ & $11.795-11.785$ & Componente 2 - U2c \\
\hline $\mathrm{s} / \mathrm{i}$ & $9.890 \pm 90^{c}$ & $\mathrm{~s} / \mathrm{i}$ & & $\mathrm{s} / \mathrm{i}$ \\
\hline UCIAMS 21641 & $9.585 \pm 25$ & $-23,9$ & $11.081-10.928$ & Componente 3 - U2d \\
\hline UCIAMS 21642 & $9.555 \pm 25$ & $-32,6$ & $11.070-10.951$ & Componente 3 - U2d \\
\hline UCIAMS 21647 & $9.550 \pm 20$ & $-22,4$ & $11.069-10.953$ & Componente 3 - U2d \\
\hline UCIAMS 21635 & $9.545 \pm 20$ & $-24,3$ & $11.068-10.954$ & Componente 3 - U2d \\
\hline UCIAMS 21646 & $9.545 \pm 20$ & $-27,0$ & $11.068-10.954$ & Componente 3 - U2d \\
\hline UCIAMS 21640 & $9.525 \pm 20$ & $-27,3$ & $11.064-11.024$ & Componente 3 - U2d \\
\hline UCIAMS 21638 & $9.525 \pm 20$ & $-23,6$ & $11.064-11.024$ & Componente 3 - U2d \\
\hline Uru-248 b & $9.280 \pm 200$ & $-21,0$ & $11.124-9.901$ & Componente 3 - U2d \\
\hline Beta-156973 & $9.120 \pm 40$ & -26.2 & $10.298-10.176$ & Componente 3 - U2d \\
\hline Uru-246 & $8.570 \pm 150$ & $-21,0$ & $10.119-9.093$ & Componente 3 - U2d \\
\hline
\end{tabular}

Nota: Las edades fueron obtenidas a partir de carbón vegetal. Todas tomadas de Suárez 2011a con excepción de la datación de $9.890 \pm 90$ a.p. ${ }^{\mathrm{c}}$

${ }^{a}$ Calibración con Calib 7.0. con la curva para el hemisferio sur: SHCAL13. ${ }^{14} \mathrm{C}$ según Hogg et al. 2013.

b Método estándar.

c Datación publicada por Austral 1995.

$\mathrm{s} / \mathrm{i}=\sin$ información. 
de artefactos formatizados que incluyen hojas y láminas retocadas, raederas, raspadores y núcleos -uno piramidal de hojas-, así como restos óseos de fauna del Pleistoceno (Equus sp.) y actual (Myocastor coipus, Rhea americana y Leporinus sp.). Es interesante la presencia de un artefacto que podría ser definido como un perforador con espolón o punta sobre lasca spurred flake graver (Osbor 2014) que se describe más adelante.

El componente 2 tiene entre 12.008 y 11.785 años cal. a.p. (Tabla 1), contiene exclusivamente material lítico. Se ubica en la unidad estratigráfica U2c (Figura 4), se recuperaron en este componente artefactos formatizados como bifaces muy delgados y puntas de proyectil, artefactos cortantes sobre láminas, raspadores, raederas, núcleos, choppers y cepillos.

El componente 3 tiene entre 11.081 y 9.120 años cal. a.p. (Tabla 1), se ubica en la unidad estratigráfica U2d (Figura 4) donde se recuperaron artefactos líticos asociados con fauna del final de Pleistoceno y actual. Los artefactos recuperados incluyen puntas proyectil, raspadores, raederas, láminas y percutores, entre otros. Los vestigios de fauna recuperados en el componente 3 incluyen taxa de fauna extinguida representada por Equus sp. y Glyptodon sp., destacándose una plaqueta fracturada en dos partes y varios osteodermos de gliptodonte.

La fauna actual recuperada en los componentes 1 y 3 presenta una relativa alta variedad de clases con registros de ave, mamíferos y pez. La asociación entre Equus sp. (caballo americano), Glyptodon sp. y artefactos líticos en el componente 3 , indicarían la coexistencia de dos especies de fauna del Pleistoceno con humanos, en el noroeste de Uruguay durante el Holoceno temprano.

\section{Principales Características del Conjunto de Artefactos Utilizados Durante el Poblamiento de Uruguay}

La excelente resolución cronológica, estratigráfica y cultural de Pay Paso 1 ofrece por primera vez en Uruguay la oportunidad de avanzar en el conocimiento del conjunto de artefactos utilizados por los grupos tempranos. Recientemente se realizaron progresos en relación con la base regional de recursos líticos y la identificación de nuevas canteras-taller de arenisca silicificada, ágata traslúcida, jaspe, ópalo y cuarzo; lo cual permitió definir a la Región Arqueológica Catalanes Nacientes Arapey (RACNA de ahora en adelante) (Figura 1) en el Norte Uruguay (Suárez 2010). Desde esta región arqueológica durante el final del Pleistoceno se trasladó ágata traslúcida hasta campamentos residenciales ubicados en el río Uruguay medio, distantes entre 140 y 170 km de los sitios tempranos Pay Paso 1 y K87 (Suárez 2011b).

El conjunto de artefactos recuperados en los componentes culturales tempranos de Pay Paso 1 incluye 124 artefactos formatizados (Tabla 2) y 1390 desechos de talla. A continuación se realiza por cuestiones de espacio una breve descripción de los diferentes artefactos hallados en los componentes culturales, ya que un estudio detallado y exhaustivo de los mismos así como de los desechos de talla se realizó en Suárez (2011a).

\section{Puntas de proyectil tempranas}

\section{Puntas Tigre}

En el componente 2 se recuperaron puntas de proyectil con pedúnculo ancho que se describen a continuación y fueron denominadas puntas Tigre (Suárez 2011a). La punta ilustrada en la Figura 5A tiene limbo triangular corto con lados convexos, aletas rectas y pedúnculo diferenciado. Este último presenta bordes o lados rectos, abrasión en ambos bordes y $90^{\circ}$ de ángulo entre el limbo y pedúnculo. La sección de la punta es biconvexa simétrica y fue manufacturada en arenisca silicificada de grano fino. Esta punta sufrió un intensivo proceso de reactivación sobre todo del primer tercio del limbo.

La punta ilustrada en la Figura 5B presenta limbo triangular corto con lados rectos y pedúnculo diferenciado. La base del pedúnculo tiene una fractura similar a la punta descrita previamente, los lados del pedúnculo son paralelos levemente convexos. Los lados del limbo son rectos, los ángulos del limbopedúnculo son de $90^{\circ}$ en un lado y $110^{\circ}$ en otro. La pieza fue manufacturada en madera silicificada y fue extensivamente reavivada.

Otras puntas con morfología similar a las del componente 2 han sido recuperadas en superficie en el sitio Pay Paso 1, en el centro de Uruguay y en el sur de Brasil (Corteletti 2008; Suárez 2011a), por lo que es un diseño recurrente en la región. En síntesis, las puntas Tigre fueron definidas a partir de la evidencia arqueológica, cronológica y estratigráfica de tres sitios tempranos K87, Pay Paso 1 y Laguna Canosa en el noroeste de Uruguay (Suárez 2011a). 
Tabla 2. Artefactos líticos formatizados recuperados en la excavación del sitio Pay Paso 1. Lithic artifacts recovered in the Pay Paso 1 excavation.

\begin{tabular}{|c|c|c|c|c|c|c|c|c|c|}
\hline \multirow{2}{*}{ Artefactos } & \multirow{2}{*}{$\mathrm{n}$} & \multirow{2}{*}{$\%$} & \multicolumn{5}{|c|}{ Materia prima } & \multicolumn{2}{|c|}{ Formabase } \\
\hline & & & A.S. ${ }^{a}$ & Ágata & C.S. ${ }^{b}$ & M.S. ${ }^{c}$ & Otras & Lasca & Guijarro \\
\hline Bifaz & 8 & 6,45 & 6 & & & 1 & $1^{\mathrm{d}}$ & 8 & \\
\hline Puntas proyectil & 6 & 4,83 & 3 & & & 2 & $1^{\mathrm{e}}$ & 6 & \\
\hline Raspadores & 33 & 26,61 & 27 & 2 & 3 & 1 & & 14 & 19 \\
\hline Raederas & 12 & 9,67 & 10 & 1 & 1 & & & 10 & 2 \\
\hline Lascas retocadas & 12 & 9,67 & 9 & 2 & & & $1^{\mathrm{f}}$ & 12 & \\
\hline Láminas retocadas & 4 & 3,22 & 1 & 2 & 1 & & & 4 & \\
\hline $\begin{array}{l}\text { Hojas rastros } \\
\text { complementarios }\end{array}$ & 5 & 4,03 & 2 & 3 & & & & 5 & \\
\hline $\begin{array}{l}\text { Filo natural con } \\
\text { rastros complementarios }\end{array}$ & 11 & 8,87 & 5 & 5 & 1 & & & 9 & 2 \\
\hline $\begin{array}{l}\text { Artefactos formatización } \\
\text { sumaria }\end{array}$ & 6 & 4,83 & 4 & 1 & 1 & & & 5 & 1 \\
\hline Núcleos & 13 & 10,48 & 12 & 1 & & & & & 13 \\
\hline Chopper & 8 & 6,45 & 8 & & & & & & 8 \\
\hline Otros ${ }^{\mathrm{g}}$ & 6 & 4,83 & 5 & 1 & & & & 2 & 4 \\
\hline Total & 124 & 100 & 92 & 18 & 7 & 4 & 3 & 75 & 49 \\
\hline & & & $74,19 \%$ & $14,5 \%$ & $5,64 \%$ & $3,22 \%$ & $2,41 \%$ & $60,48 \%$ & $39,51 \%$ \\
\hline
\end{tabular}

Nota: ${ }^{\text {a }}$ A.S $=$ Arenisca Silicificada $;{ }^{\mathrm{b}}$ Caliza Silicificada $;{ }^{\mathrm{c}}$ M.S. $=$ Madera Silicificada $;{ }^{\mathrm{d}}$ Basalto; ${ }^{\mathrm{e}}$ Jaspe; ${ }^{\mathrm{f}}$ Materia prima no determinada; ${ }^{\mathrm{g}}$ Cepillo-Rabot, Artefacto sobre nódulo con retoques $(n=2)$, Perforador, Nódulo probado, Nódulo rastro complementario.

\section{Puntas Pay Paso}

El componente 3 presenta puntas de proyectil con pedúnculo corto y base cóncava escotada (Figura 6). La punta ilustrada en la Figura 6A tiene limbo triangular largo con lados levemente convexos y pedúnculo diferenciado con hombros redondeados. La base del pedúnculo es cóncava profunda (escotada), los lados del pedúnculo son cóncavos expandidos hacia la base y presentan abrasión en ambos bordes. La base del pedúnculo fue adelgazada con un negativo triangular en cada lado. Los lados del limbo son levemente convexos y presenta hombro redondeado. La sección transversal donde finaliza el limbo es bitriangular (helicoidal) y en el centro del limbo es biconvexa simétrica. El retoque en ambas caras presenta negativos paralelos cortos irregulares y laminares.

Estas puntas que han sido denominadas Pay Paso (Suárez 2003) se recuperaron también en estratigrafía en el sitio K87 (MEC 1989). Puntas de similares características morfológicas fueron halladas además en superficie en el sitio Pay Paso 1 y Pay Paso 7, en sitios del río Uruguay medio (Hilbert 1991), en la cuenca del río Negro medio (Suárez y Gillam 2008), en la costa atlántica (López Mazz 2013) y en el sur de Brasil (Corteletti 2008).

Las puntas tempranas Tigre y Pay Paso son puntas de dardo que probablemente fueron lanzadas con estólica o propulsor. Si bien no tenemos evidencia de propulsores en contextos tempranos, se han recuperado ganchos de propulsores de huesos y asta en contextos del Holoceno en sitios arqueológicos de la desembocadura del río Negro en Uruguay (Figura 7).

\section{Bifaces}

Se recuperaron en total siete bifaces en las excavaciones del sitio Pay Paso 1 (ver ejemplo Figura $8 \mathrm{~A}$ ), dos en el componente 2 y cinco en el componente 3 . Un bifaz de similar morfología al de Pay Paso 1 -ilustrado en la Figura 8A- fue recuperado por Hilbert (1985:521) en el sitio K87 

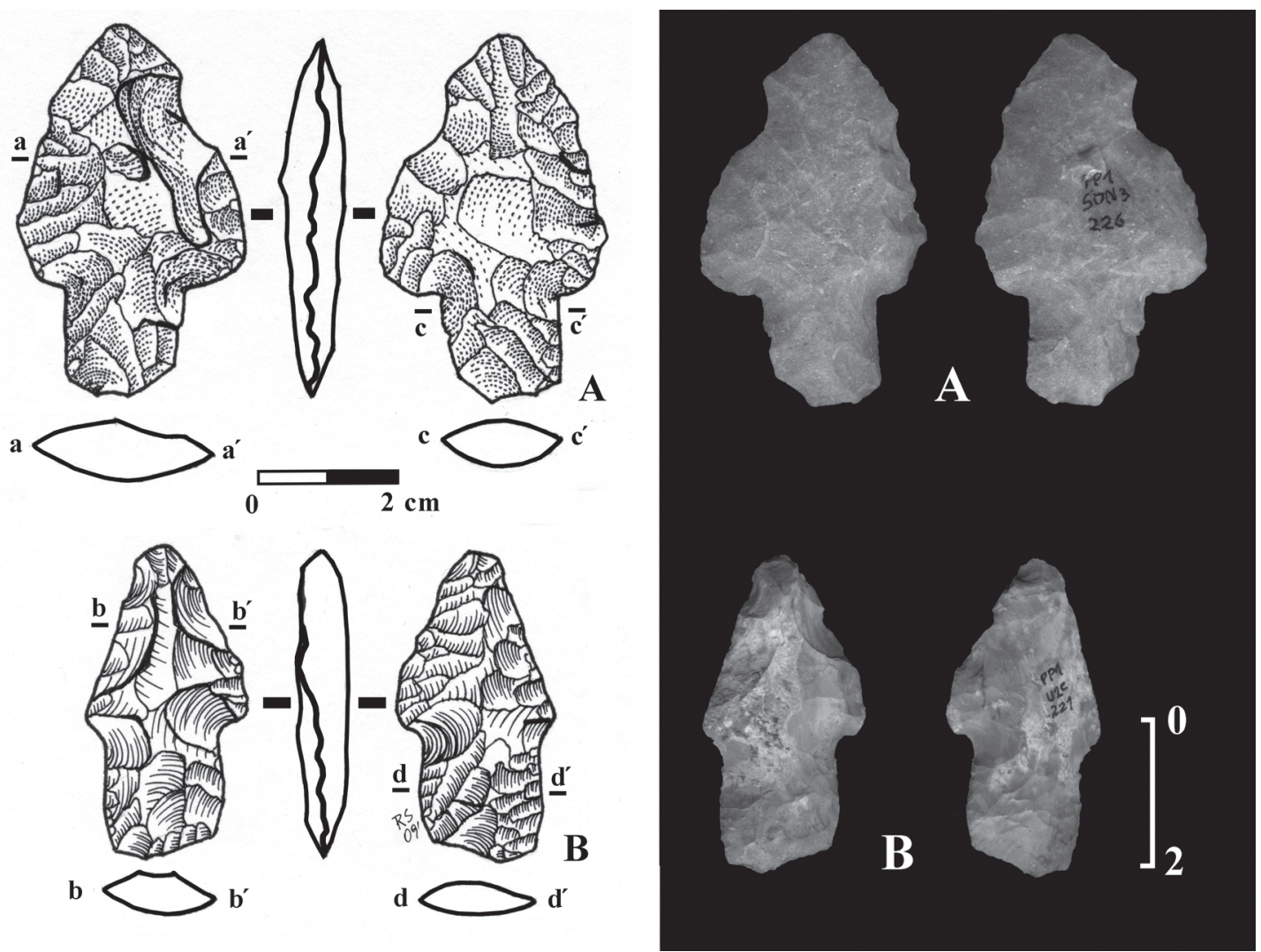

Figura 5. Puntas Tigre (K87) recuperadas en el componente 2 datadas entre 12.008 y 11.785 años cal. a.p, sitio Pay Paso 1. Tigre points from component 2 dated between 12,008 and 11,785 yr cal. BP, Pay Paso 1 site.

(Figura 8B y descripción más abajo). En superficie en Pay Paso se han hallado varias decenas de bifaces con diversas morfologías y en diferentes etapas de adelgazamiento (Figura 9). Los dos bifaces del componente 2 presentan similares características técnicas y morfológicas (forma oval y sección biconvexa simétrica). Uno de los bifaces está entero y el otro fracturado. El bifaz ilustrado en la Figura $8 \mathrm{~A}$ tiene retoque perimetral y fue manufacturado a partir de una lasca delgada. El total del perímetro o borde del filo fue formatizado bifacialmente por medio de retoques paralelos irregulares y retoques. El filo observado con lupa de $15 x$ presenta en diferentes sectores microlascados y microastilladuras bifaciales como trazas de utilización (pulidos y microastilladuras), por ese motivo se interpreta la pieza como cuchillo bifacial de filo retocado perimetral y no como una preforma. Este bifaz se manufacturó en una variedad de arenisca silicificada de grano muy fino con tonalidades rojas y rosadas.
Aproximadamente sobre un tercio de una cara de la pieza se extiende una fuerte adherencia de $\mathrm{CaCO}_{3}$. Un bifaz muy similar al arriba descrito en su morfología y técnica de manufactura -aunque más espeso- se presenta en la Figura 8B, este bifaz se recuperó en el sitio K87 (Arroyo del Tigre) datado en ca. 12.400 años cal. a.p. (Hilbert 1985:521 Figura 63).

\section{Hojas y láminas}

Entre el conjunto de artefactos de Pay Paso 1 se recuperaron hojas y láminas (Figura 10). Las hojas fueron descriptas en detalle en otra publicación (Suárez 2011b); sin embargo, en este trabajo se hacen algunas puntualizaciones sobre su presencia en el sitio. Se entiende por hoja a una lasca especializada que fue removida intencionalmente de un núcleo preparado, es dos veces o más larga que ancha, exhibe por lo menos dos crestas o aristas que indican 

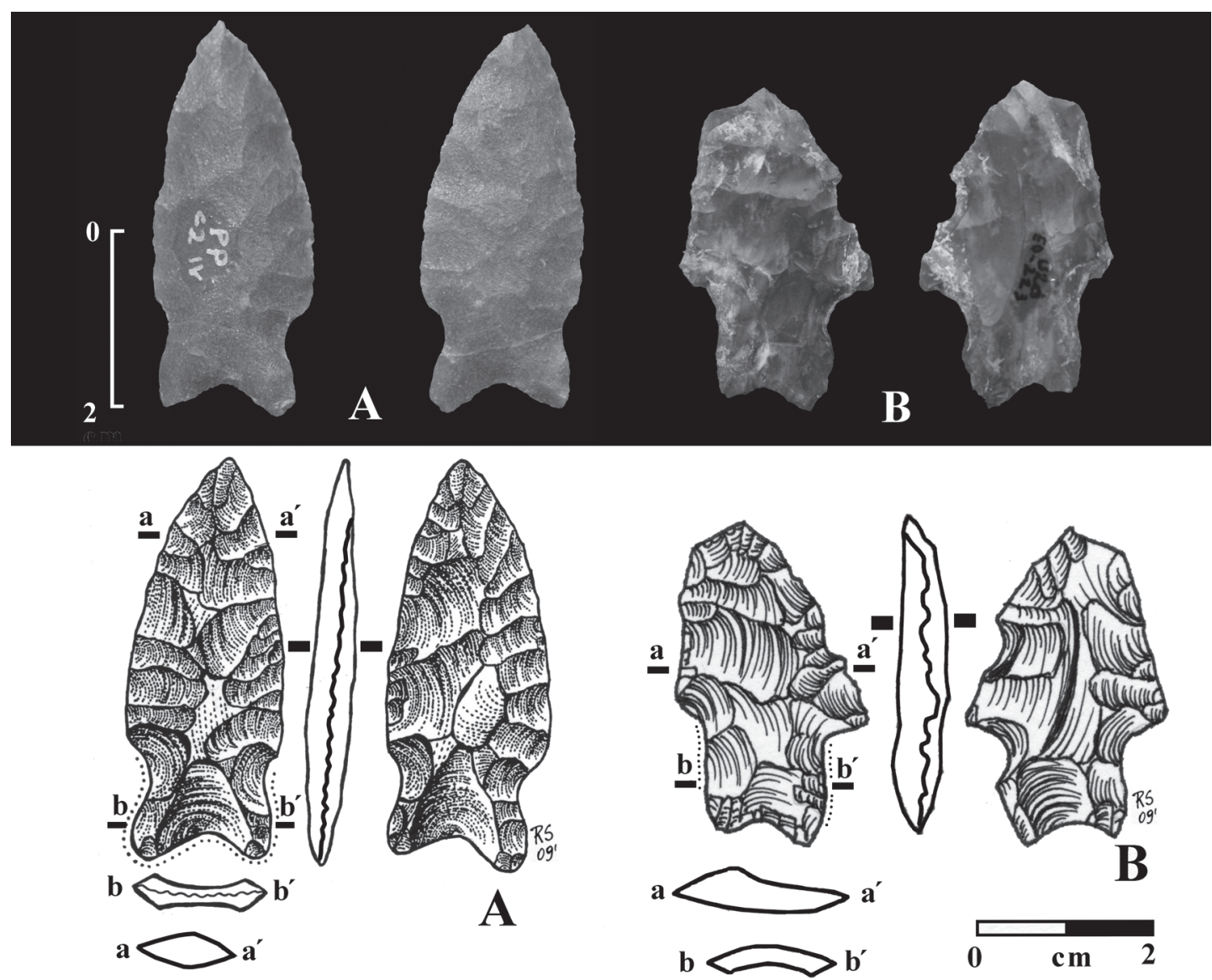

Figura 6. Puntas Pay Paso del componente 3 datadas entre 11.081 y 9.120 años cal a.p. Pay Paso points from component 3, dated between 11,081 and 9,120 yr cal BP.

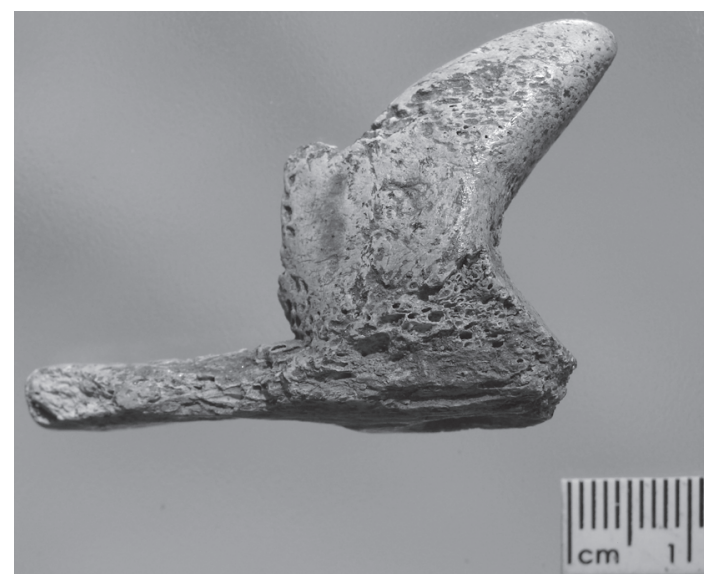

Figura 7. Gancho de propulsor o estólica en hueso proveniente del sitio La Blanqueada (Holoceno) (Museo del Indio y la Megafauna - Maldonado).

Bone atlatl hook from La Banqueada site (Holocene). (Museo del Indio y la Megafauna - Maldonado). negativos de extracciones anteriores paralelas o subparalelas en la cara dorsal, presentan por lo general lados paralelos y sección triangular o trapezoidal (sensu Collins 2002:191). Lámina es una lasca por lo menos dos veces más larga que ancha, presenta extracciones de lascados multidireccionales en el dorsal y pueden o no producirse durante adelgazamiento o reducción bifacial. En cambio, la producción de hojas presenta intencionalidad de obtener una determinada forma de artefacto a partir de núcleos preparados para tales fines (Collins 2002).

Las materias primas utilizadas para obtener hojas en el componente 1 son ágata traslúcida (Figura 10A) y arenisca silicificada de grano fino (Figura $10 \mathrm{~B}$ y D), las mejores materias primas a nivel local. Las hojas son todas mayores a $\operatorname{los} 3 \mathrm{~cm}$, por lo tanto, no son microhojas según Collins (2002:10) y las secciones son triangulares y trapezoidales. 

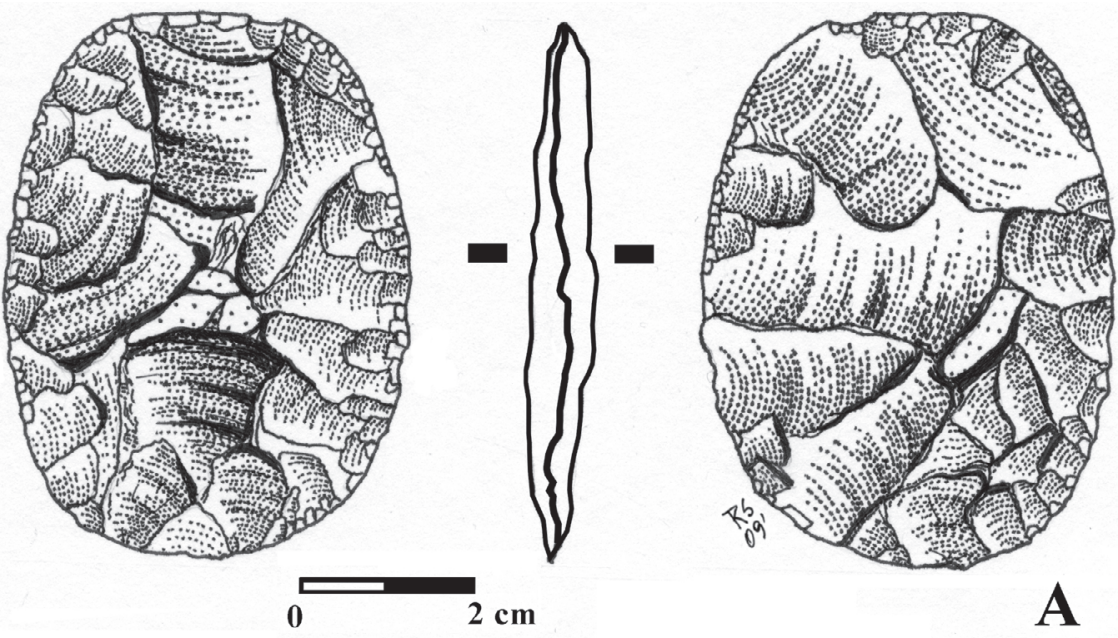

A

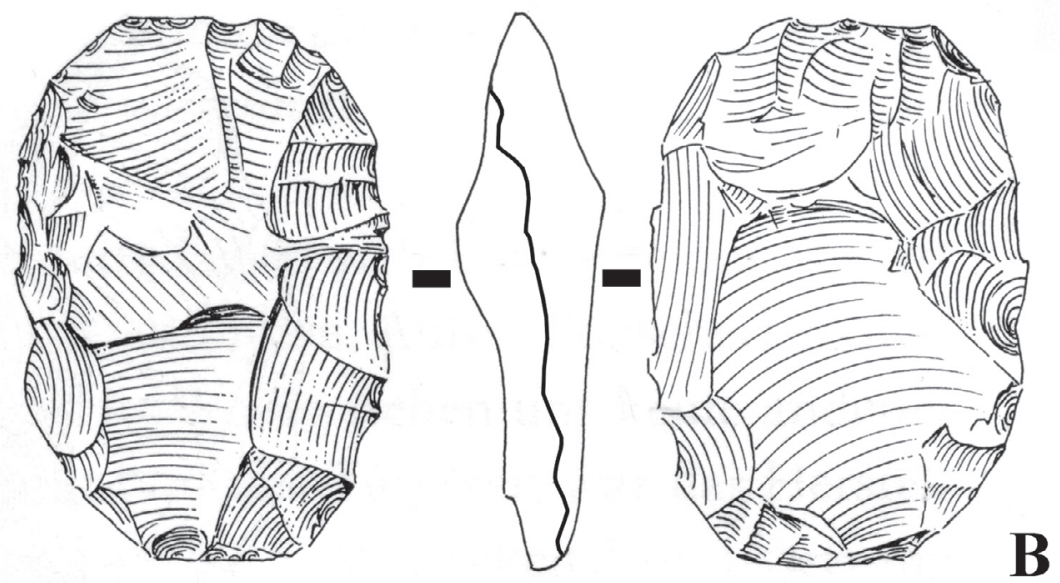

Figura 8. Bifaces ovalados tempranos. (A) Recuperado en el componente 2 del sitio Pay Paso 1 (12.008 y 11.785 años cal a.p.). (B) Recuperado en el sitio K87 (ca. 12.500 años cal. a.p.) (Levemente modificado de Hilbert 1985:521 Figura 63,2).

Early oval bifaces. (A) Recovered in component 2 of Pay Paso 1 site (between 12,008 and 11,785 years cal BP). (B) Recovered in excavations at the $K 87$ site $(12,500$ cal yr. BP). (Slightly modified from Hilbert 1985:521 Figure 63,2).

La presencia de hojas en la base del componente 1 permite realizar una serie de consideraciones tecnológicas y morfológicas sobre su producción en los contextos tempranos del noroeste del Uruguay. La intención de obtener hojas indica la existencia de dicha tecnología hacia los ca. 13.000 años cal. a.p. por los talladores que visitaron Pay Paso 1. Aunque la sola presencia de hojas no es suficiente para afirmar que existió una tecnología lítica orientada hacia la producción de las mismas, el hallazgo de un núcleo de extracción de hojas (Suárez 2011b:371 Figura 7) en el mismo componente cultural, suma evidencia en ese sentido.
El núcleo recuperado en el componente 1 es piramidal y presenta extracciones combinadas de hojas y lascas (Suárez 2011b:371 Figura 7A). Este núcleo es definido como un núcleo agotado de producción de hojas (blade depleted core) (Collins 2002:11 Figura 2.2a). Otro núcleo de extracción de hojas sobre canto rodado se recuperó en el componente 2 (Suárez 2011b:371 Figura 7B).

\section{Raederas}

Se recuperaron cuatro artefactos clasificados como raederas (sensu Aschero 1983) en el componente 1, 


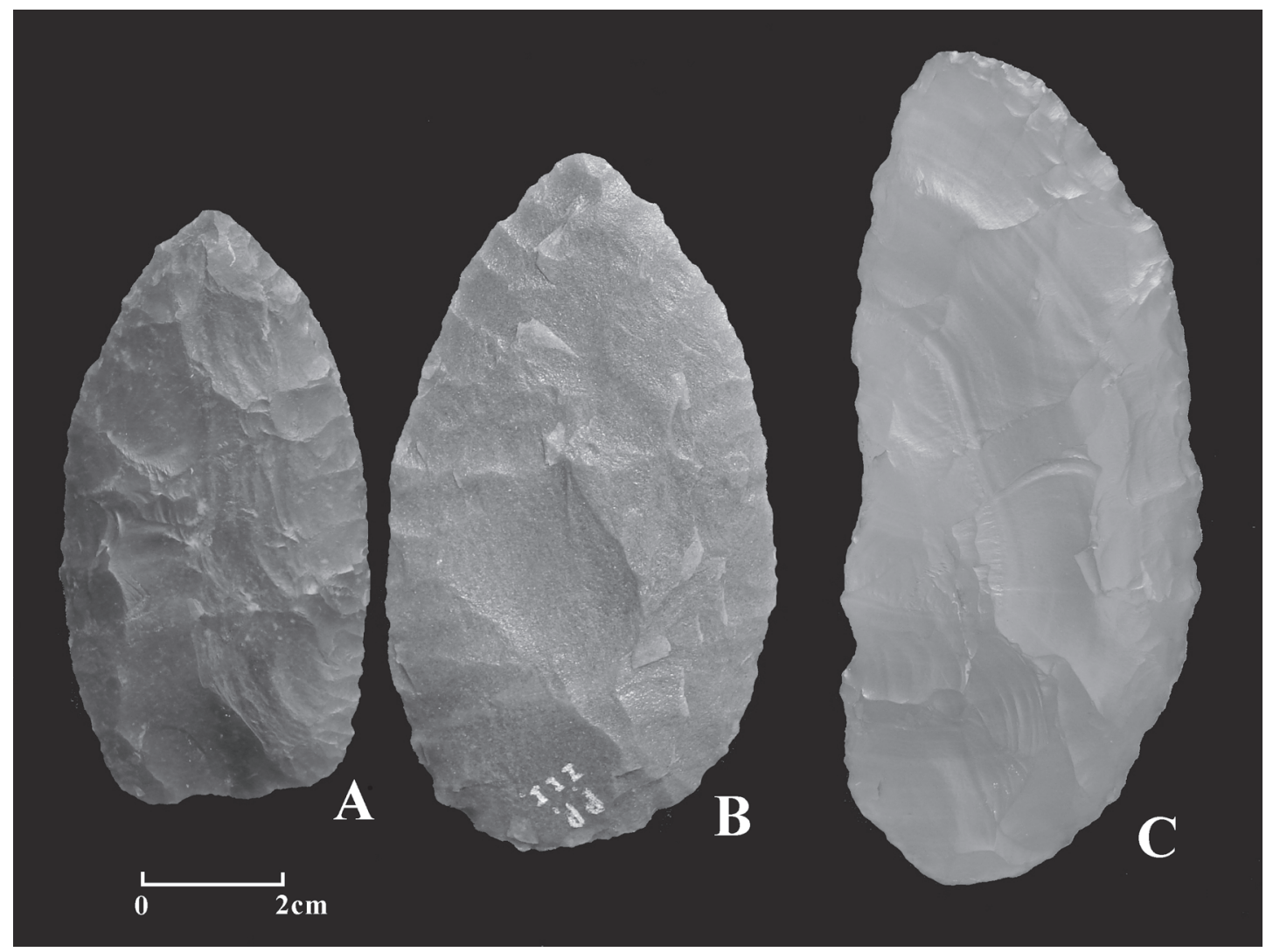

Figura 9. Bifaces recuperados en la localidad Pay Paso. (A) Con acanaladura y "nipple isolation" en la base (caliza silicificada); (B) Oval (arenisca silicificada); (C) Asimétrico con negativos de lascas ultrapasadas (overshot flakes) (ágata traslucida). Bifaces recovered from the Pay Paso locality. (A) With fluting and nipple isolation at the base (silicified limestone), (B) Oval (silicified sandstone), (C) Asymmetric with overshot flake scars (translucent agate).

las cuales fueron manufacturadas a partir de lascas muy anchas y relativamente delgadas. Tres de las raederas presentan semejanzas en su morfología o diseño que las hace homogéneamente similares en su técnica de manufactura/producción. Estas piezas tienen ángulos de bisel de entre $31^{\circ}$ y $43^{\circ}$. Las formas base utilizadas para manufacturar las raederas son lascas muy delgadas y muy anchas, tienen las siguientes dimensiones: $100-70 \mathrm{~mm}$ de largo por 70-40 mm de ancho y entre $9-11 \mathrm{~mm}$ de espesor. Esta clase de raederas presenta una cresta o arista que se extiende longitudinalmente en la misma dirección del eje técnico (Figura 11). La cara dorsal presenta extracciones de lascas estandarizadas en la misma dirección que se obtuvo la lasca base. La cara ventral no tiene bulbo de percusión que fue eliminado deliberadamente.

La marcada estandarización en el diseño, tecnología, morfología (Figura 11 A y B), y quizás función de las raederas, puede indicar la intención de producir una determinada forma base que sería una lasca ancha y delgada. Dichas formas base podrían haber sido obtenidas de grandes núcleos bifaciales como el que se ilustra en la Figura 12, el cual tiene $213 \mathrm{~mm}$ de largo por $163 \mathrm{~mm}$ de espesor, y que fue recuperado en las canteras de arenisca silicificada de la RACNA (Figura 1).

\section{Perforador con espolón sobre lasca}

En el contexto del componente 1 datado entre 12.802 y 12.470 años cal. a.p. se recuperó un artefacto expeditivo de singulares características. El artefacto se manufacturó a partir de una lasca fracturada de ágata traslúcida, tiene $31 \mathrm{~mm}$ de largo por $22 \mathrm{~mm}$ de ancho y $5 \mathrm{~mm}$ de espesor máximo, presenta una delicada punta-espolón -realizado con pequeños retoques-que tiene 2,0 $\mathrm{mm}$ de largo por 1,5 $\mathrm{mm}$ 

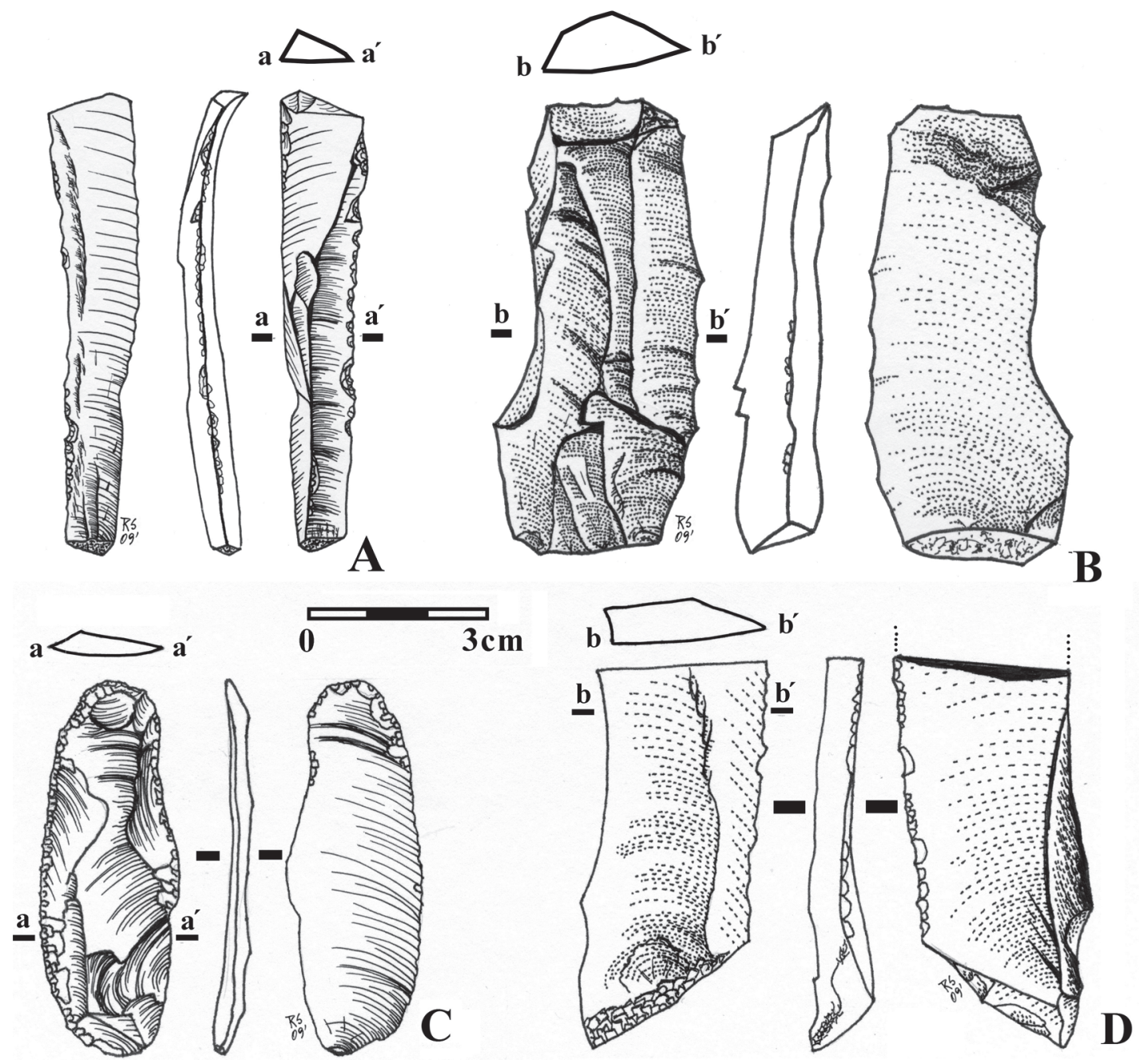

Figura 10. (A) Hoja arista simple, (B) hoja de arista doble, ambas provenientes del componente 1 (entre ca. 12.802 y 12.470 años cal. AP), (C) Lámina y (D) hoja de arista simple, ambas del componente 2 (ca. 12.008 años cal. AP).

Blades (A) and (B) from component 1 (ca. 12,802-12,470 yr cal. BP). (C) Bladelet and (D) blade from component 2 (ca. 12.008 yr cal. BP).

de ancho y un espesor de 0,5 mm (Figura 13). El espolón fue realizado con delicados retoques que continúan en el borde frontal del filo donde se ubica una punta prominente. Artefactos similares a estos han sido recuperados en decenas de sitios paleoindios de América del Norte, una reciente publicación de Osborn (2014:51-61) realiza una puesta al día, análisis y síntesis de hallazgos de esta clase de artefactos en contextos tempranos datados durante el Younger Dryas en Norteamérica. Sorprende la similitud del artefacto recuperado en el componente 1 del sitio Pay Paso 1 (Figura 13) con los artefactos ilustrados por Osborn (2014 Figuras 2 y
3). Las características tecnológicas de los artefactos como por ejemplo la forma base (lasca fracturada) así como la morfología y tamaño de los artefactos son prácticamente idénticos, lo mismo sucede con las medidas y dimensiones del espolón (punta) del artefacto de Pay Paso 1 que está en el rango de los artefactos de Norteamérica (Osborn 2014: tabla 3:53), la cronología de los artefactos también es similar. Varias interpretaciones se han sugerido para esta clase de artefactos, desde que son copases para cortar artefactos circulares de hueso, asta, calcita, concha, etc. artefactos para manufacturar y reparar implementos de caza, o que son agujas para hacer 

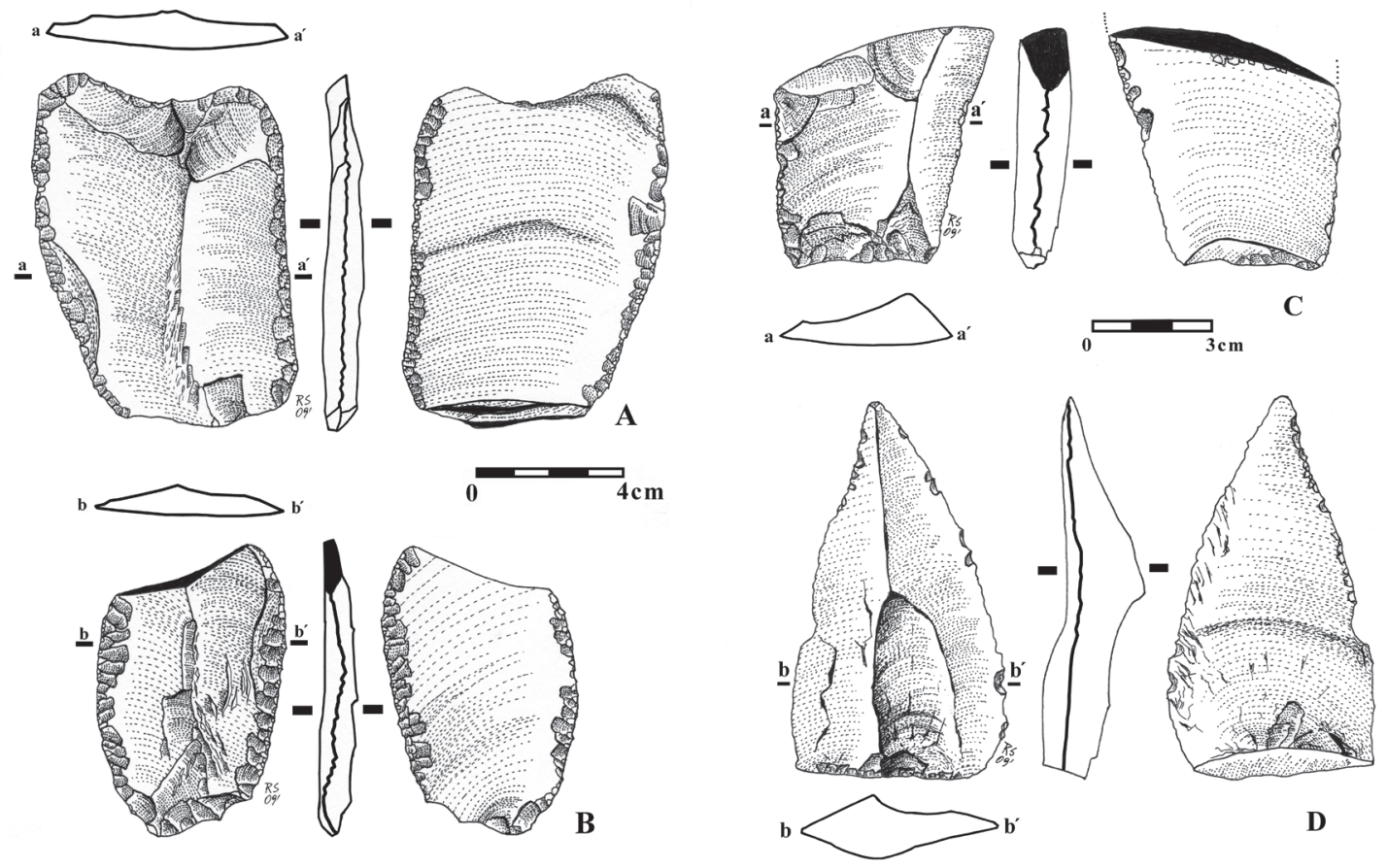

Figura 11. (A) y (B) Raederas del componente 1 recuperadas en el sitio Pay Paso 1 datadas entre 12.802 y 12.470 años cal. a.p. (C) y (D) Artefactos unifaciales asociados a las puntas Tigre, componente 2 sitio Pay Paso 1, datados entre 12.008 y 11.785 años cal. a.p. (A)-(B) Side-scrapers from component 1 of Pay Paso 1 site, dated to 12.802-12.470 yr cal. BP. (C)-(D) Unifacial artifacts associed to Tigre points, component 2 Pay Paso 1 site dated 12,008-11,785 yr cal. BP.

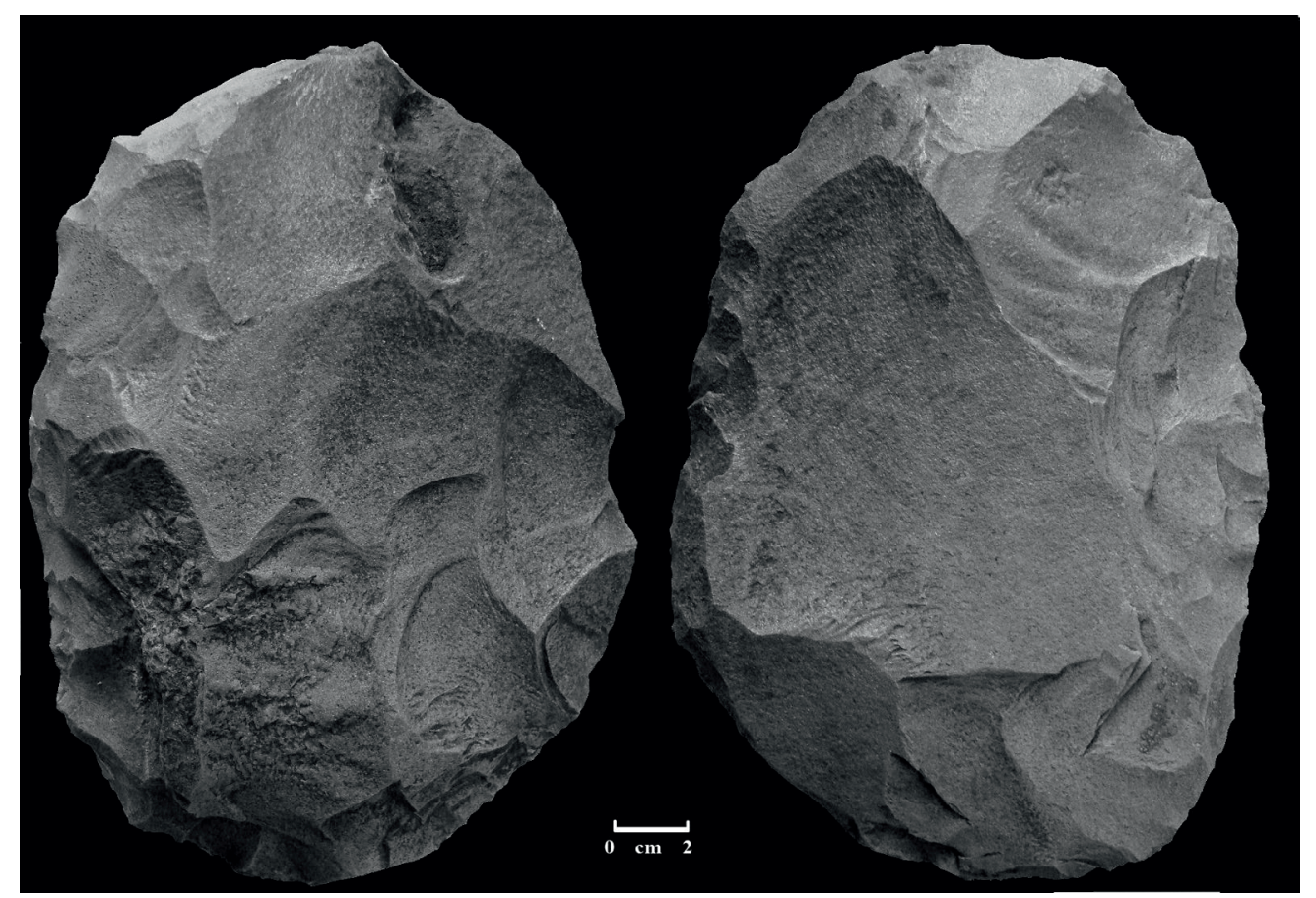

Figura 12. Núcleo bifacial de la Región Arqueológica Catalanes Nacientes Arapey (RACNA). Museo Histórico departamental de Artigas.

Bifacial core from Región Arqueológica Catalanes Nacientes Arapey. Museo Histórico departamental de Artigas. 

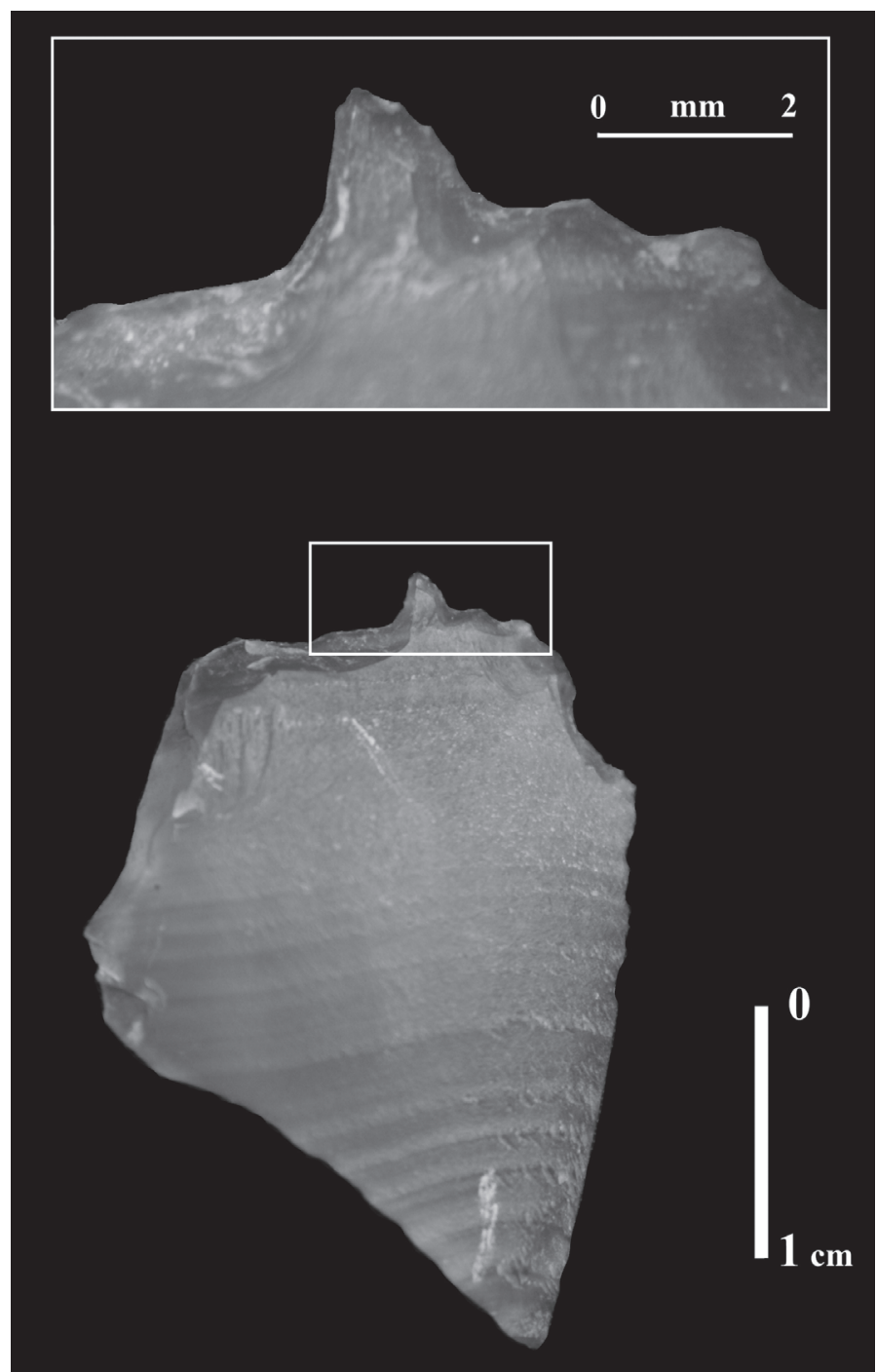

Figura 13. Perforador con espolón sobre lasca proveniente del componente 1 (ca. 12.802-12.470 años cal a.p.) sitio Pay Paso 1 (ágata translúcida). Spurred flake gravers from component 1 ( ca. 12,802-12,470 yr cal BP) Pay Paso 1 site (translucent agate).

tatuajes, entre otros (Osborn 2014). Sin embargo, Osborn (2014) siguiendo a H. Irwing sugiere que esta clase de perforadores son una tecnología asociada a la costura y fueron utilizados por mujeres para confeccionar ojos de agujas de hueso o asta. Estos artefactos son recurrentes en contextos del final del Pleistoceno e inicio del Holoceno (Younger Dryas Cold Event), recuperados muchas veces en contextos arqueológicos con agujas de hueso (Osborn 2014: Figura 1). Osborn sugiere que durante este periodo se desarrolló una tecnología orientada hacia la confección de vestimenta con fines de abrigo, para afrontar las condiciones de frío riguroso durante los inviernos del Younger Dryas, siendo estos artefactos líticos evidencia de esa tecnología.

\section{Utilización de materias primas en Pay Paso 1}

El análisis de los desechos de talla (Suárez 2011a:102-111) y artefactos formatizados permiten conocer o determinar las frecuencias de utilización de materias primas para la talla en Pay Paso 1. Arenisca silicificada y ágata traslúcida son las rocas más utilizadas en los tres componentes culturales, 
recursos líticos que seguramente están condicionados por su disponibilidad y abundancia, tanto a nivel local como regional.

Los porcentajes de materias primas varían significativamente si se los analiza por componente cultural, demostrando preferencias y variación cronológica diferencial en la utilización de los recursos líticos. Los datos indican que para el componente 1 ágata traslúcida representa el 23,40\% de los artefactos, mientras que en el componente 2 desciende a $9,52 \%$ y en el componente 3 es menor alcanzando el 2,7\% del total de los artefactos. En este sentido, los datos obtenidos para los artefactos formatizados son coincidentes con los desechos de talla, ya que corroboran que si bien la arenisca silicificada es la materia prima más empleada en los tres componentes, hay una mayor utilización y preferencia por ágata translúcida en el primer momento de ocupación -ca. 12.800-12.500 años cal. a.p.-. Paralelamente, el porcentaje de arenisca silicificada asciende a $91,60 \%$ de los artefactos formatizados en el componente 3 y fue utilizada en el $70,21 \%$ de los artefactos formatizados del componente 1 .

Arenisca silicificada y ágata traslúcida son rocas de acceso local que pueden obtenerse en los bancos de cantos rodados del río Cuareim en las inmediaciones del sitio. Es interesante señalar que el $39,51 \%$ de los artefactos formatizados fueron producidos a partir de guijarros o cantos rodados como forma base (Tabla 2). Debido a la abundancia y disponibilidad de cantos rodados de materias primas muy buenas como arenisca silicificada y ágata, la tecnología lítica desarrollada tiene una importante base de producción inicial en la talla, reducción y adelgazamiento a partir de cantos rodados. Por otro lado, para la producción en Pay Paso 1 de artefactos bifaciales en ágata translúcida que superan los 100 $\mathrm{mm}$ de largo, se tuvo como origen a las canteras y fuentes de abastecimiento de recursos líticos de la RACNA (Suárez 2011b).

Las rocas no disponibles a nivel local presentan baja representatividad, tanto en la producción de artefactos formatizados, como en la frecuencia de los desechos de talla. Por ejemplo, la madera silicificada o xilópalo aparece representada en los desechos de talla con un $0,07 \%$ y en los artefactos formatizados alcanza el $3,22 \%$. Estos datos permiten sugerir que esta roca debió ser transportada bajo la forma de artefactos formatizados desde áreas relativamente alejadas, ya que en Pay Paso 1 los artefactos en madera silicificada son un bifaz y dos puntas de proyectil, instrumentos considerados de larga vida útil (Binford 1979; Shott y Bellenger 2007). Estos artefactos debieron haber ingresado al sitio transportados desde fuentes relativamente alejadas, fuentes secundarias se ubican en el río Uruguay a más de $14 \mathrm{~km}$ del sitio. Fuentes primarias de esta materia prima se ubican en la formación Yaguarí a más de 250 km de Pay Paso 1. Otro sitio temprano donde hay utilización de madera silicificada en contextos tempranos es K87 -arroyo del Tigre(MEC 1989), ubicado a 53,6 km al suroeste de la localidad Pay Paso.

\section{Discusión}

En relación con las puntas tempranas que se vienen recuperando en Uruguay, es necesario hacer algunas consideraciones y aclaraciones. En los componentes 2 y 3 del sitio Pay Paso se recuperaron y dataron dos tipos de puntas de proyectil que se denominaron Pay Paso y Tigre (Suárez 2003, 2011a). Inicialmente se definió a las puntas Pay Paso (Suárez 2003) como un tipo de punta temprana, datadas por primera vez en este sitio. Sin embargo, previamente se habían recuperado en el sitio K87 (Arroyo del Tigre), pero no habían sido datadas. Posteriormente, se definió un segundo tipo que se denominó Tigre, en reconocimiento al sitio donde se había recuperado por primera vez (sitio K87 Arroyo del Tigre), que fueron datadas en los sitios Pay Paso 1 y Laguna Canosa (Suárez 2011a).

Recientemente, López Mazz (2013:96) "renombra" a las puntas Tigre que se habían definido previamente (Suárez 2011a), y las denomina "puntas pedunculadas triangulares con aletas" o stemmed triangular with wings. Lo que sí son, pero este es un término extremadamente impreciso para definir un tipo de punta de proyectil. Primero, porque se basa en atributos muy generales como las "aletas", la forma general del limbo "triangular" y la presencia de pedúnculo; las aletas son uno de los atributos que más se modifican durante la vida útil de estos artefactos y ninguno de los ejemplos presentados por ese autor presenta verdaderas aletas. Segundo, porque es un término ambiguo, en Uruguay la mayoría de las puntas recuperadas son "puntas pedunculadas triangulares con aletas", que se han recuperado en sitios arqueológicos del Holoceno Medio datados entre ca. 5.440 y 4.146 años cal a.p. (Iriarte 2003: Figura 4.17) y en contextos del 
Holoceno reciente (Hilbert 1991). Por lo tanto, la denominación realizada por López Mazz (2013:9697) es general, imprecisa y confusa. Además, cabe la posibilidad de incluir dentro del mismo tipo a puntas tempranas y puntas tardías.

La morfología del pedúnculo se ha utilizado para definir las puntas con un nombre propio y específico que las identifique claramente. En Uruguay, por ejemplo, Femenías e Iriarte (2000) a partir solo de atributos morfológicos del pedúnculo definieron cuatro tipos de puntas de proyectil (Yaguanesa, Zapucay, Yaguarí y Paso del Puerto). Las puntas que se han denominado Pay Paso y Tigre siguen por esa línea; sin embargo, se avanza un paso más, pues se logró ubicar temporalmente dos tipos de puntas a partir de una sólida cronología de alta resolución (Suárez 2011a). Cuando se definieron a las puntas Tigre y Pay Paso, la nomenclatura de las mismas se realizó a partir del sitio donde se descubrieron en estratigrafía y/o dataron por primera vez, así como por la morfología del pedúnculo. En el caso de las puntas de Uruguay, lo importante cuando se nombra un tipo es la forma general del pedúnculo, los lados del mismo y la forma de la base. Definir, nombrar o agrupar en un tipo como "puntas pedunculadas triangulares con aletas" provoca confusión, ya que existen muchos tipos de puntas que tienen estos atributos en Uruguay. Dicha nomenclatura es insuficiente para distinguir a un tipo específico de punta temprana de la transición Pleistoceno Holoceno. Además, hay que acotar que esa terminología se generó en un momento cuando no se contaban con controles estratigráficos de los sitios tempranos. Fue realizada según López Mazz (2013:96) por Taddei en 1987, pero si analizamos en detalle los antecedentes bibliográficos esta denominación genérica, fue propuesta previamente hacia finales de la década de 1960. Así, Antonio Taddei menciona en una clasificación de objetos arqueológicos del río Negro medio e indica que "la mayoría (22) son del tipo pedunculadas con aletas" (Taddei 1969:71). Posteriormente en otros artículos (Taddei 1987; Taddei et al. 1977:226230) se vuelve a sugerir esa denominación, que sin dudas fue importante para caracterizar a un conjunto de artefactos, en un contexto y momento de la arqueología del Uruguay, donde no existían dataciones radiocarbónicas tempranas y se estaban dando los primeros pasos hacia una arqueología científica. Podemos indicar que la terminología utilizada por López Mazz (2013:98 Figura 3) tiene sus raíces en un periodo de la arqueología del Uruguay donde las observaciones eran generales y estaban basadas en contextos y sitios superficiales. Sin duda, en el contexto histórico de desarrollo de la disciplina a finales de la década de 1960 y mediados de la década de 1970 esta terminología suponía un adelanto en la caracterización de los conjuntos líticos de superficie. Pero en la actualidad es insuficiente para denominar a un tipo de punta de proyectil, hoy disponemos de contextos arqueológicos muy bien datados con cronologías de alta resolución que permiten avanzar en detalle el periodo de utilización de estos artefactos (Suárez 2011a). En este momento de desarrollo de la arqueología en Uruguay deberíamos denominar a las puntas de proyectil dándoles nombres propios, específicos y no generales. Si un criterio general como el utilizado por López Mazz (2013:96-98) se hubiera seguido para denominar a los diferentes tipos de puntas tempranas en América del Norte, por ejemplo, se las hubiera denominado "puntas apedunculadas lanceoladas sin aletas" que incluiría en un mismo tipo a las hoy clásicas puntas Clovis, Folsom, Agate Basin, Plainview, Mesa y Goshen, entre otras (Stanford et al. 1999).

La excavación del sitio Pay Paso 1 permitió identificar tres componentes culturales, definidos a partir de evidencia cultural-arqueológica, estratigráfica y cronológica. Es interesante señalar la presencia de diferentes morfologías de puntas de proyectil, similar a lo que sucede en otras regiones del continente. Por ejemplo, una variabilidad tecnológica cada vez más marcada es identificada a partir de diferentes puntas de proyectil para el final del Pleistoceno y Holoceno temprano, lo cual comienza a registrarse en diferentes regiones del cono sur, como por ejemplo en la costa pacífica (Jackson et al. 2011). Más al norte en la costa norte de Perú, Dillehay et al. (2011) han identificado una sucesión de ocupaciones tempranas caracterizada por diferentes tipos de puntas de proyectil. Por lo tanto, las puntas Pay Paso y Tigre identificadas en el noroeste de Uruguay se integran al debate que señala una importante diversidad cultural relacionada con diferentes ambientes ocupados durante el poblamiento de América del Sur.

La identificación de una tecnología orientada hacia la producción de hojas al iniciarse la ocupación del sitio Pay Paso 1 entre 12.802 y 12.692 años cal. a.p. (10.930-10.880 años a.p.) permite señalar cierta contemporaneidad con la tecnología de hojas Clovis 
de América del Norte (Bradley et al. 2010; Collins 2002; Waters y Stafford 2007). No se argumenta aquí que la tecnología de hojas que se reconoce en Pay Paso 1 es la misma, similar o desciende de la tecnología de hojas Clovis. Aunque existen diferencias que deben investigarse en profundidad, lo importante es que comienza a identificarse en contextos arqueológicos tempranos en América del Sur este tipo de tecnología. Deberemos explicar cómo en dos regiones muy distantes entre sí, a más de 10.000 km, en América del Norte y América del Sur surgen hacia 13.000 años cal. a.p. (12.900 años a.p.) ambas tecnologías de hojas. La contemporaneidad y amplia distancia geográfica entre ambas tecnologías excluye cualquier posibilidad de vincularlas directamente. Si bien resta mucha investigación por realizar, se puede adelantar a modo de hipótesis que quizás el nexo entre ambas tecnologías podría buscarse en un ancestro común vinculado con el conocimiento tecnológico del Paleolítico Superior que ingresó al continente americano hacia el final del Último Máximo Glacial (ca. 24.000-18.000 años cal a.p.) por cualquiera de las rutas posibles de ingreso que se manejan actualmente (p.ej., Erlandson 2001; Goebel et al. 2008; Miotti 2006; Stanford y Bradley 2012).

Una tecnología asociada a la costura desarrollada por mujeres (Osborn 2014) comienza a evidenciarse indirectamente a partir del material lítico recuperado en Pay Paso 1 durante el poblamiento del norte de Uruguay. El perforador con espolón-punta sobre lasca ilustrado en la Figura 13 es idéntico a los artefactos líticos asignados como herramientas utilizadas para realizar perforaciones de ojos de agujas de hueso (Osborn 2014).

\section{Conclusiones}

Las planicies de Uruguay estaban ocupadas por humanos hace por lo menos 13.000 años cal. a.p., quienes conocían y manejaban diferentes técnicas de talla para la producción de puntas de proyectil, hojas y artefactos unifaciales. La obtención de hojas se realizó a partir de núcleos piramidales. Además se prepararon núcleos bifaciales muy grandes que superan los $200 \mathrm{~mm}$ de donde se extrajeron lascas anchas para manufacturar tanto artefactos unifaciales (raederas), como para obtener lascas-soporte para confeccionar puntas de proyectil. Por otro lado, se reconocen preformas bifaciales que exhiben nipple isolation y doble acanaladura en la base, así como negativos de lascas ultrapasadas. Algunos de estos bifaces fueron preformas para manufacturar puntas de proyectil, donde se utilizó como técnica de talla la reducción bifacial completa desde etapas iniciales, intermedias y finales de adelgazamiento bifacial (Suárez 2006).

Existió una interesante diversidad en el armamento (puntas de proyectil) utilizado por los cazadoresrecolectores tempranos desde el final del Pleistoceno hasta el Holoceno Temprano en el Sureste de América del Sur. Circularon en esta región tres tipos de puntas de proyectil: Cola de Pescado o Fell 1, Tigre y Pay Paso, que tienen cierta continuidad en el tiempo y pudieron también ser contemporáneas. Las puntas Tigre datadas en el sitio Pay Paso 1 entre 12.008 y 11.785 años cal. a.p. (10.205-10.115 años a.p.) se han recuperado además en sitios superficiales del norte y centro de Uruguay, así como en el sur de Brasil (Corteletti 2008; Suárez 2011a).

Las puntas Pay Paso datadas en el componente 3 del sitio homónimo entre 11.081 y 9.120 años cal. a.p. (9.585-8.570 años a.p.) circularon en el norte, centro y sur de Uruguay, así como en el sur de Brasil durante el Holoceno Temprano.

Los grupos tempranos que exploraron el sureste de América del Sur debieron adaptarse a la extinción de la fauna del Pleistoceno, así como a la renovación de la fauna y vegetación ocurrida hacia el inicio del Holoceno Temprano. Esto a su vez asociado a las oscilaciones climáticas y paleoambientales estimuló la reorganización social y cultural, favoreciendo las innovaciones tecnológicas de nuevos y diversos diseños de puntas de proyectil, como los que comienzan a registrarse durante el poblamiento de Uruguay y las planicies del sureste de América del Sur.

Agradecimientos: a los editores César Méndez y Kurt Rademaker de este número por invitarme a presentar este artículo. Una versión preliminar del mismo fue originalmente expuesta en el simposio Early Lithic Techologies:Beyond Regional Projectile Point Typologies en el $77^{\text {th }}$ anual meeting of the Society of American Archaeology en Tennessee. National Geographic Society (USA), The WennerGren Foundation for Anthropological Resarch (USA) y CONICYT (Uruguay) financiaron diferentes etapas de la investigación de campo y laboratorio realizada en el sitio Pay Paso 1. Actualmente la investigación sobre los primeros americanos en 
Uruguay es financiada por la Agencia Nacional de Investigación e Innovación (ANII) (FCE-2009-12453) y CSIC proyecto I+D 2012 Universidad de la República, Uruguay. Deseo agradecer especialmente a Francisco "Pancho" Mena quien me estimuló en las conversaciones e intercambio de ideas que tuvimos en el congreso The First Peopling of Americas organizado por UNESCO en Puebla (México, 2013) para que publicara el gancho de estólica o propulsor que presento en la Figura 7. Los evaluadores con sus eficaces comentarios y sugerencias permitieron mejorar el artículo. Los editores de la revista colaboraron en que el texto fuera más claro y entendible.

\section{Referencias Citadas}

Aschero, C. 1983. Ensayo para una clasificación morfológica de artefactos líticos aplicada a estudios tipológicos comparativos. Revisión 1983. Apéndice A-C. Cátedra de Ergología y Tecnología. Facultad de Filosofía y Letras. Universidad de Buenos Aires. Buenos Aires. Manuscrito en posesión del autor.

Austral, A. 1995. Los cazadores del sitio estratificado Pay Paso hace 10.000 años. En Arqueología en el Uruguay, editado por M. Consens, J.M. López y C. Curbelo, pp. 212-218. AUA, Montevideo.

Binford, L.R. 1979. Organization and formation processes: Looking at curated technologies. Journal of Anthropological Research 35:255-273.

Bird, J. 1969. A comparison of South Chilean and Ecuadorian "Fishtail" projectile points. The Kroeber Anthropological Society Papers 40:52-71

Bosch, A., J. Femenías y A. Olivera 1980. Dispersión de las puntas de proyectil líticas pisciformes en el Uruguay. Actas III Congreso Nacional de Arqueología Uruguaya (sin paginar). CEA, Montevideo.

Bradley, B., M.B. Collins y A. Hemmings 2010. Clovis Technology. International Monographs in Prehistory. Archaeological Series 17. Ann Arbor, Michigan.

Bradley, B. y D. Stanford 2004. The North Atlantic ice-edge corridor: a possible Palaeolithic route to the New World. World Archaeology 36:459-478.

Castiñeira, C., M. Carrillo, J. Charlin y J. Baeza 2011. Análisis de morfometría geométrica en Puntas Cola de Pescado del Uruguay. Latin American Antiquity 22:335-358.

Collins, M. 2002. Clovis Blade Technology. University of Texas Press, Austin.

Collins, M. y J. C. Lohse 2004. The nature of Clovis Blades and Blade Cores. En Entering America Northeast Asia and Beringia before the Last Maximum Glacial, Northeast Asia and Beringia, editado por D.B. Madsen, pp. 159-183. University of Utah Press, Salt Lake City.

Corteletti, R. 2008. Patrimonio Arqueológico de Caxias do Sul. Editora Nova Prova, Porto Alegre.

Dillehay, T.D. (ed.) 2011. From Foraging to Farming in the Andes. New Perspectives on Food Production and Social Organization. Cambrige University Press, Cambridge.

Erlandson, J.M. 2001. The archaeology of aquatic adaptations: Paradigms of a New Millennium. Journal of Archaeological Research 9:287-350
Figueira, J.H. 1892. Los Primitivos Habitantes del Uruguay. Ensayo Paleoetnológico. Imprenta Artística Dornaleche y Reyes, Montevideo.

Femenías, J. y J. Iriarte 2000. Puntas de proyectil del Río Negro Medio: Primer paso en la construcción de una cronología cultural. En Arqueología de las Tierras Bajas, editado por A. Durán y R. Bracco, pp:481-489. Ministerio de Educación y Cultura, Montevideo.

Flegenheimer, N., C. Bayón, M. Valente, J. Baeza y O. Femenías 2003. Long distance tool stone transport in the Argentine Pampas. Quaternary International 109-110:49-64.

Goebel, T., M. Waters y D.H. O'Rourke 2008. The Late Pleistocene dispersal of Moderns Humans in the Americas. Science 319:1497-1502.

Hilbert, K. 1985. Archäologishe Fundplätze des Río Uruguay, Tigre und des Mandiyú, Republik Uruguay. Beiträge Zur Allegemeinen und Vergleichenden Archäologie Band 7:447-561.

Hilbert, K. 1991. Aspectos de la Arqueología en el Uruguay. Verlang Philipp Von Zabern, Mainz Am Rhein.

Hogg, A.G., Q. Hua, P.G. Blackwell, M. Niu, C.E. Buck, T.P. Guilderson, T.J. Heaton, J. Palmer, P. Reimer, R.W. Reimer, C. Turney y S.H.H. Zimmerman 2013. SHCAL13 Southern Hemispere Calibration, 0-50,000 years cal BP. Radiocarbon 55:1-15.

Iriarte, J.2003 Mid-Holocene Emergent Complexity and Landscape Transformation: The Social Construction of early Formative Communities in Uruguay, La Plata Basin. Tesis de doctorado inédita. University of Kentucky, Kentucky.

Jackson, D., A. Maldonado, M. Carré y R. Seguel. 2011. Huentelaquén Cultural Complex: The Earliest Peopling of the Pacific Coast in the South-America Southern Cone. En Documents Préhistoiques Peuplements et Préhistoire en Amériques, editado por D. Vialou, pp. 221-232. Editions du Comité des Travaux Historiques et Scientifiques, París.

López Mazz, J.M. 2013. Early human occupation of Uruguay: Radiocarbon database and archaeological implications. Quaternary International 301:94-103.

Ministerio Educación y Cultura (MEC) 1989. Misión de Rescate Arqueológico de Salto Grande. Tomo 2. Montevideo.

Miotti, L.L. 2006. La Fachada Atlántica como puerta de ingreso alternativa de la colonización de América del Sur durante la Transición Pleistoceno/Holoceno. Actas II Simposio Internacional El Hombre Temprano en América, editor J. C. Jiménez, pp. 156188. INAH, México D.F. 
Nami, H. 2007. Research in the Middle Río Negro Basin (Uruguay) and the Paleoindian Occupation of the Southern Cone. Current Anthropology 48:164-171.

Osborn, A. 2014. Eye of the Needle: cold stress, clothing, and sewing technology during the Younger Dryas Cold Event in North America. American Antiquity 79:45-68.

Piñeiro, G. y R. Suárez 2012 Paleosuelos en el Holoceno del río Cuareim. Actas III Jornadas del Cenozoico en Uruguay. DINAMIGE. 58-63. Montevideo.

Politis, G. 1991. Fishtail Projectile Points in the Southern Cone of South America: An Overview. En Clovis: Origins and Adaptations, editado por R. Bonnichsen y K. Turnmire, pp. 287-301. Center for the Study of the First Americans. Oregon University Press, Corvallis.

Shott, M.J. y J.A.M. Ballenger 2007. Biface reduction and the measurement of Dalton Curation: A Southeastern United States case study. American Antiquity 72:153-175.

Stanford, D. 1999. Paleoindian archaeology and Late Pleistocene environments in the plains and Southwest United States. En Ice Age Peoples of North America, editado por R. Bonnichsen y K.L. Turmine, pp. 281-339. Center for the Study of First Americans, Corvallis.

Stanford, D. y B. Bradley 2012. Across Atlantic Ice. The Origin of America's Clovis Culture. University of California Press, Los Angeles.

Suárez, R. 2000. Paleoindian Occupations in Uruguay. Current Research in the Pleistocene 17:78-80.

Suárez, R. 2003. Paleoindian components of Northern Uruguay: New data for Early human occupations of the Late Pleistocene and Early Holocene. En Where the South Winds Blow: Ancient Evidences From Paleo South Americans, editado por L Miotti, M. Salemme y N. Flegenheimer, pp. 29-36. Center for the Study of the First American y Texas A \& M University Press, Texas.
Suárez, R. 2006. Comments on South American Fisthail Points: Design, reduction sequences and function. Current Research in the Pleistocene 23:69-72.

Suárez, R. 2010. Arqueología Prehistórica en la Localidad Arroyo Catalán Chico. Investigaciones Pasadas, Replanteo y Avances Recientes. Depto. Publicaciones CSIC. Universidad de la República, Montevideo.

Suárez, R. 2011a. Arqueología durante la Transición Pleistoceno Holoceno: Componentes Paleoindios, Organización de la Tecnología y Movilidad de los Primeros Americanos en Uruguay. British Archaeological Reports 2220, International Series, Archaeopress, Oxford.

Suárez, R. 2011b. Movilidad, acceso y uso de ágata translúcida por los cazadores-recolectores tempranos durante la transición Pleistoceno Holoceno en el Norte de Uruguay (ca. 11,000-8500 A.P). Latin American Antiquity 22:359-383.

Suárez, R. y C. Gillam 2008. The Paleoindian database of Uruguay: Collection survey and GIS Data development. Current Research in the Pleistocene 25:200-202.

Suárez, R. y J.M. López 2003. Archaeology of the Pleistocene/ Holocene transition in Uruguay: An overview. Quaternary International 109-110:65-76.

Taddei, A. 1969. Un yacimiento de cazadores superiores del Medio Río Negro, Uruguay. Pesquisas Antropológicas 20:5778. São Leopoldo.

Taddei, A. 1987. Algunos aspectos de la Arqueología Prehistórica en el Uruguay. Estudios Atacameños Investigaciones Paleoindias al Sur de la Línea Ecuatorial, editado por L. Núñez y B. Meggers, pp. 62-93. Universidad del Norte, San Pedro de Atacama.

Taddei, A., J. Campos y A. Bosch 1977. Las industrias líticas arqueológicas de los ríos Tacuarembó Grande y Chico. Actas $V$ Encuentro de Arqueología del Litoral, pp. 225-261. CEA, Fray Bentos.

Waters, M.R. y T.W. Stafford Jr. 2007. Redefining the Age of Clovis: Implications for the peopling of the Americas. Science 315:1122-1126

\section{Nota}

1 Las edades se presentan en años calendario antes del presente (años cal. a.p), entre paréntesis se presentan algunas veces las edades en años C14 antes del presente (años a.p.); fueron calibradas con el programa Calib 7.0. con la curva para el hemisferio sur: SHCAL13.14C según Hogg et al. 2013. 